\title{
Chapter 18 \\ Red Snow-When the Climate Bleeds: \\ A Nordic Art and Science Project Aimed at Overcoming Climate Apathy Through Collaboration Between Artists and Scientists
}

\section{Bente Elisabeth Endresen}

\begin{abstract}
This chapter describes the transformative potential of arts and science collaboration. The aim of the Nordic art and science project "Red Snow-When the Climate Bleeds" which was undertaken in 2014-2016 was to increase people's awareness of the accelerating climate changes we are witnessing in the twenty-first century. This chapter shows how people can be encouraged to take action for the care of our planet and to live in a more sustainable way. The project was centred around an exhibition, consisting of artwork and scientific presentations, established collaboration with students at schools and universities and was implemented in four countries. In order to highlight the urgency of the need for change, the project showed some future scenarios presented by climate researchers. With the use of visual art, music and dance, it was possible to reach a larger audience than science alone could: this opened people's hearts and minds to new knowledge. The chapter concludes that the collaboration between the arts and science is increasingly important. Art can successfully go beyond the mental mindset, and speak directly to the emotions of the audience, and once works of art have made an impression, visitors are generally more open to new knowledge.
\end{abstract}

Keywords Climate change $\cdot$ Climate crisis $\cdot$ Climate apathy $\cdot$ Nordic art Sustainability $\cdot$ Collaboration

\subsection{Introduction}

In my years as an artist and curator, I have had profound experiences of how art has the capacity to reach people's hearts. Art can successfully go beyond the mental mindset and speak directly to the hearts and emotions of the audience, thus gaining a completely different dialogue. I have witnessed people overwhelmed by emotions, just by looking at a painting or other artwork, be it naturalistic or abstract. It has

B. E. Endresen ( $\square)$

Freelance Visual Artist, 8420 Knebel, Denmark 
been surprising to me that art can affect the viewer just as strongly emotionally as music can affect listeners. And once works of art have made an impression, I have observed that visitors are generally more open to new impressions, new information and knowledge. In my belief, the vibrations sent out by art, by colour, form, and the energy the artist has put into her work, are being reflected in the attentive observer. And in this way, it opens up new reflections and insights.

The aim of the Nordic art and science project "Red Snow-When the Climate Bleeds"1 which was undertaken in 2014-2016, was to increase people's awareness of the accelerating climate changes we are witnessing in the twenty-first century. We wanted to encourage people to take action to take better care of our Planet and to live in a more sustainable ${ }^{2}$ way (Red Snow-When the Climate Bleeds, 2015). The project was centred around an exhibition, consisting of artwork and scientific presentations, and was held in four countries, starting in Greenland's Cultural House Katuaq in Nuuk, Greenland in 2014. The next exhibition was at the North Atlantic House in Copenhagen, Denmark in 2015, followed by an exhibition in the Nordic House, Reykjavik, Iceland. In 2016, the exhibition was held in the Nordic House in Torshavn, Faroe Islands. Music events, meetings with local artists and scientists, and lectures were also held at the exhibition venues. Where possible, we established collaboration with students at schools and universities.

When I initiated the "Red Snow"- project in 2009, I was sure that art could be a way to both give the visitors an artistic experience, and also be a door-opener to get the public to take in new information about climate change, which at that time was not an everyday topic. This was confirmed by the participants' reactions during the project's journey around the Nordic countries.

For example, during the first exhibition in Nuuk, Greenland in 2014, one young student, clearly shaken, after having heard a public lecture on climate change, asked in a trembling voice, "Is this the worst-case scenario"? We regretfully had to answer: "No, this is only a moderate projection of the speed at which we see the glaciers melting and retreating". For a moment she looked devastated. But then she steadied herself and asked in a voice that was both loud and clear, "And what can we do"?

This young person made a strong impression upon me and gave me hope. She had seen the exhibition, watched a drum-dance performance from Greenland and attended a scientific lecture on how the Arctic ice cap is melting and at what pace the glaciers in the Arctic are disappearing, because of climate change. And now she was taking part in the discussion about what could be done to help. The young student became a symbol of the impact the project, presented here, was able to have on people. By taking in knowledge that was obviously new to her, and reacting with an intention and a will to act on the facts, she was proof that the aim of the project "Red Snow - When the Climate Bleeds" was achievable.

\footnotetext{
${ }^{1}$ For more information, see: https://benteelisabeth.dk/climate-art/red-snow/.

${ }^{2}$ Sustainability focuses on meeting the needs of the present without compromising the ability of future generations to meet their needs. I define sustainability as Gaia Education does, as consisting of four dimensions; the social -, the ecological - , the economic - and the worldview dimension. Ref: https://www.gaiaeducation.org/elearning-programmes/design-for-sustainability/.
} 


\subsection{The Purpose of the Project "Red Snow-When the Climate Bleeds"}

As mentioned in the introduction, the purpose of the Nordic art and science project "Red Snow-when the Climate Bleeds" was to raise awareness of the already visible effects of today's climate change and make more people realize that something must be done. In order to highlight the urgency of the need for change, we wanted to show some future scenarios presented by climate researchers and make the public aware, via neutral scientific information, of how current human activity is affecting the climate. With the use of visual art, music and dance, we hoped to be able to reach a larger audience than science alone could: we wanted to open people's hearts and minds to new knowledge. Our aim was also to show that art and creativity can be sources of inspiration to find new solutions. For decades, climate scientists have been trying in vain to get the attention of both the public and politicians, on the ofteninconvenient facts about the climate change we are witnessing. We wanted to impart some of this knowledge, whilst maintaining a sense of hope and an encouragement that it is possible, with the help of creativity, do something to turn the tide.

Our project provided a multifaceted approach to the theme of climate change, involving both art and science. On the artistic side, there were various contemporary contributions, interpreting the subject through sculpture, painting (e.g. Fig. 18.1), drawings, installations, photographs, sound, drums, music played with a variety of instruments, song and dance. The scientific researchers came with observations from multiple fields to facilitate new insights: biology, geology, meteorology, glaciology, botany, physical geography, oceanography, palaeontology and polar exploration. The project had a core group of twelve Nordic artists and researchers from Greenland, Iceland, Norway, Denmark and Faroe Islands, with me as the project manager as well as artist. Our work was shown at the four exhibition places. At each location, contributions from local actors were added, and we were working alongside a host of dedicated employees at the exhibition venues in Nuuk, Copenhagen, Reykjavik and Faroe Islands. Our project was intended to be a wake-up call, inspiring action on both individual and collective levels, resulting in a coming forth of the many, with the same question as the young student who asked: "What can we do"?

This idea of providing neutral scientific facts alongside art, with imaginative interpretations of the consequences of climate change, seemed to be a rather new and powerful combination to Nordic Culture Point and Nordic Culture Fund, who provided crucial funding support, and to the four exhibition venues that provided their space and invaluable helpful staff. A booklet Red Snow-When the Climate Bleeds (2015) was also printed. 
Fig. 18.1 "Red

Snow-When the Climate Bleeds". Painting by Bente Elisabeth Endresen, oil on canvas, $60 \times 200 \mathrm{~cm}$, copyright by the author

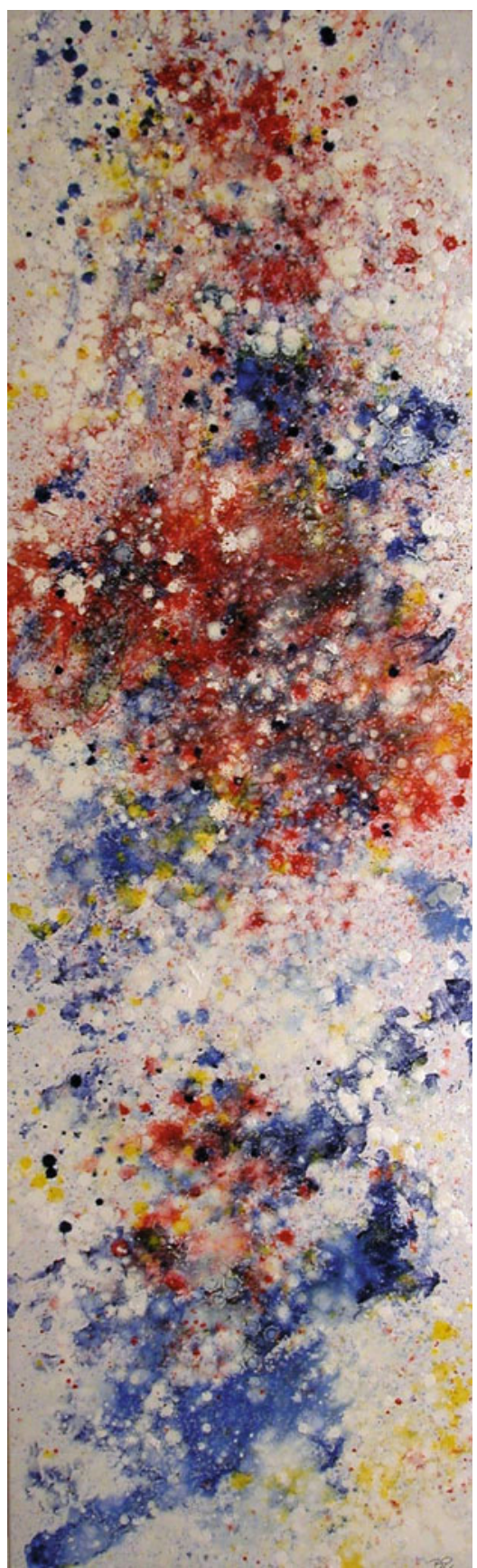




\title{
18.3 The Project's Choreography
}

The former President of Iceland, Vigdís Finnbogadóttir, opened the Project's exhibition in Reykjavik accompanied by performances from local choirs and musicians (Red Snow-When the Climate Bleeds, 2015). In her opening speech, the former president acknowledged accelerating climate change and the unprecedented rate at which the world's glaciers are melting. She continued:

\begin{abstract}
It is more urgent than words can express, that we stop this man-made natural catastrophe that threatens the Earth through drastic climate change and threatens most of all that life which cannot thrive without having firm ice underfoot. With Greenlandic drumming we now try to rouse those who are still not awake to this, the greatest threat to mankind. Mixed in with the Greenlandic drumming we hear the voices of Nordic scientists who know better than anyone else the terrible effects of the glacial melting. The choir now singing of the 'Red Snow' also includes musicians and artists, showing what cannot be expressed in words. I especially welcome the collaboration between artists and scientists, lending their voices together to this choral suite about melting ice. I fully believe that this concerted effort of science and art will amplify the sound so that it may reach those who have been sleeping.
\end{abstract}

Similar openings were held at other locations. Figure 18.2 shows drumming activity at the opening of the Red Snow exhibition in the Faroe Islands.

As visitors entered the main exhibition, they were met by recordings of music inspired by the sound of waterfalls crashing onto rocks, calving glaciers and raven's screams. These provided a familiar soundscape from the environment we value so highly, as a backdrop to a scene of alarming sculptures of human figures, halfsubmerged in water. Some of these figures had, in panic, reached out for the nearest thing available, obviously useless in the situation. The shrinking of the Icelandic glaciers due to global warming over the next 50 years was illustrated on a large screen. Polar bears were portrayed wandering restlessly over lush green grass, unable to find food. There were large paintings of melting glaciers, red algae on snow and streams of water, eroding soil and new plants emerging; all illustrating the transformation we are witnessing in the arctic environment. In special workshops at the exhibition venues scientists explained their in-depth research into the most recent climate changes, including the effect of freezing water from melting glaciers upon the North Atlantic Current along the coast of southeast Greenland and on invasive species threatening Arctic flora. Videos, photographs, and posters presented scientific insights into these visible effects of climate change upon the arctic environment, as well as scientific data on the state of both glaciers, ice, and snow. As a part of the exhibition, a polar explorer expressed her fascination with the beauty of the Arctic, as she described in a poem the silence between falling snowflakes. After this sensory bombardment, workshop participants were asked to stop and reflect, then to write down their fears for climate change and their hopes for the future. Over their heads hovered giant dream catchers.

Visitors to the exhibition could also participate in both a lecture and an open discussion on the visible impact of climate change on the Arctic environment. The lecture was occasionally interrupted by traditional drum-dance and song from Greenland, performed by fellow participants from the project's workshop. Bringing music, 


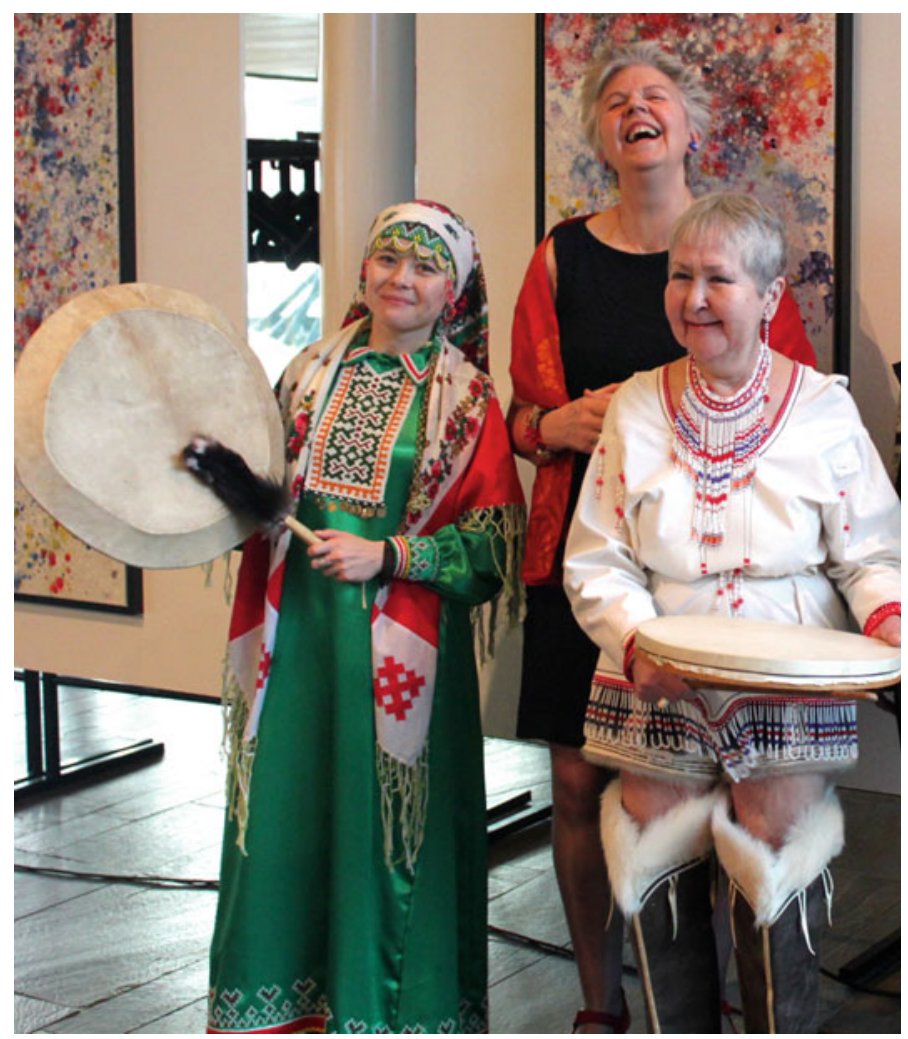

Fig. 18.2 From the opening of project "Red Snow-When the Climate Bleeds" in Torshavn in the Faroe Islands. From the left, Vera Kondrateva, Sibiria, Bente Elisabeth Endresen, Denmark/Norway and Pauline Motzfeldt, Greenland. Two paintings by Bente Elisabeth Endresen from the Red Snow exhibition are visible in the background. (C) Bente Elisabeth Endresen

drums and dance into play added a flavour of ancient Arctic culture to the already intense atmosphere in the lecture hall.

\subsection{Effects of the Collaboration Between Art and Science in the "Red Snow" Project}

By bringing together two universes as divergent as art and science at all exhibition venues, we created a forum that enabled the two to mutually inspire one another and in so doing, reach out to a wider public. The most visible effect of the "Red Snow" project was the profound impact it had on the exhibition visitors, who displayed a willingness to take in new information and to change their perception of climate change. Previously, people in the Arctic have often reacted to the prospect of climate 


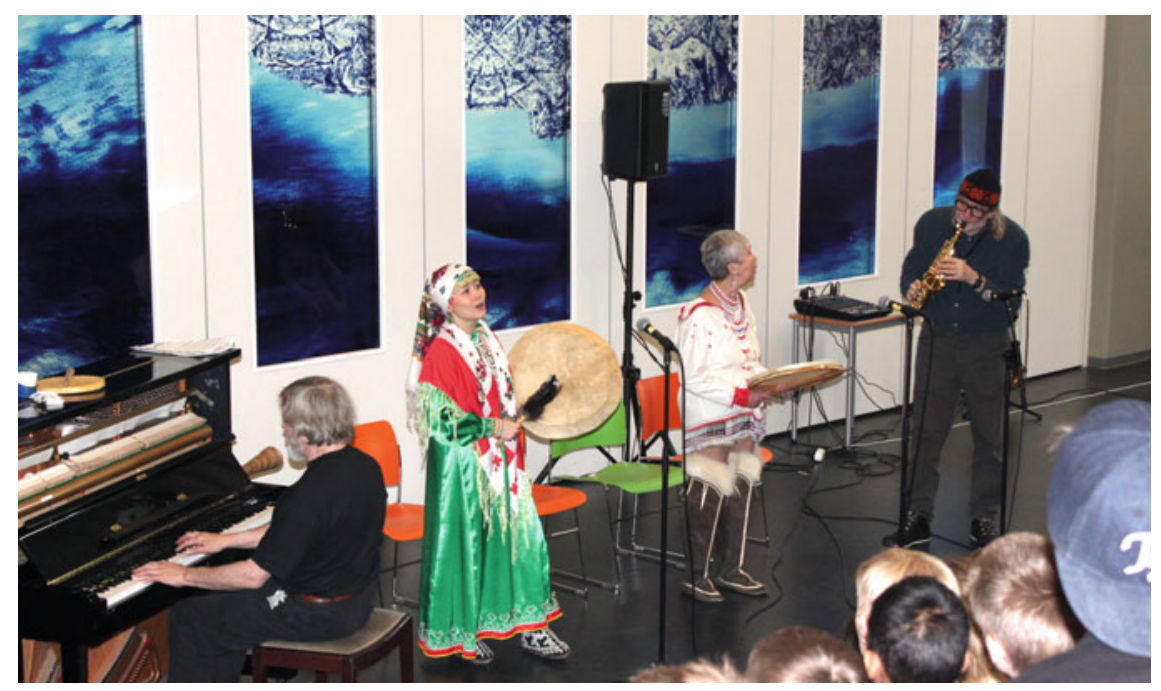

Fig. 18.3 Project "Red Snow-When the Climate Bleeds". School concert in Argjahamni School in the Faroe Islands, conducted by Kristian Blak at piano. (C) Bente Elisabeth Endresen

change with a laugh and the comment: "It would be nice to have warmer summers up here in the north". With our project we felt we had managed to achieve our aim of reaching out to a broad range of people, making a noticeable impression upon them and opening their eyes to the reality of climate change. We were especially touched to witness the impact the project had on the younger participants.

Exhibition visitors included art lovers, who responded with great interest to the presentation of research on climate change: information they were clearly not used to seeking out. Conversely, visitors who were primarily interested in the scientific approach, spontaneously expressed enthusiasm towards the rich experience they felt, by being presented with works of art they in many cases would not have sought out, had it not been for the project's combination of art and science. All visitors were interested in the scientific facts of climate change, but our overall impression was that it was the younger participants who spontaneously became more actively involved in finding solutions to what could be done to counteract the crisis.

Students and school classes motivated by their enthusiastic and committed teachers had an immediate response (see Figs. 18.3 and 18.4). They became very preoccupied with the theme and immediately began thinking about what they could do. One of the school teachers in the Faroe Islands, Teitur, ${ }^{3}$ told us:

"Our pupils are 7-12 years old. At first, I was in doubt. How could this exhibition possibly succeed in speaking to these young children? They do not even know what climate change is. But then we came upon a TV screen where the children saw pictures of how climate change has affected the landscape over the decades. Suddenly, it was as if a light bulb had been switched on in their heads and the message behind the art began to make sense. The

\footnotetext{
${ }^{3}$ https://benteelisabeth.dk/climate-art/red-snow/ Video interview with Teitur.
} 


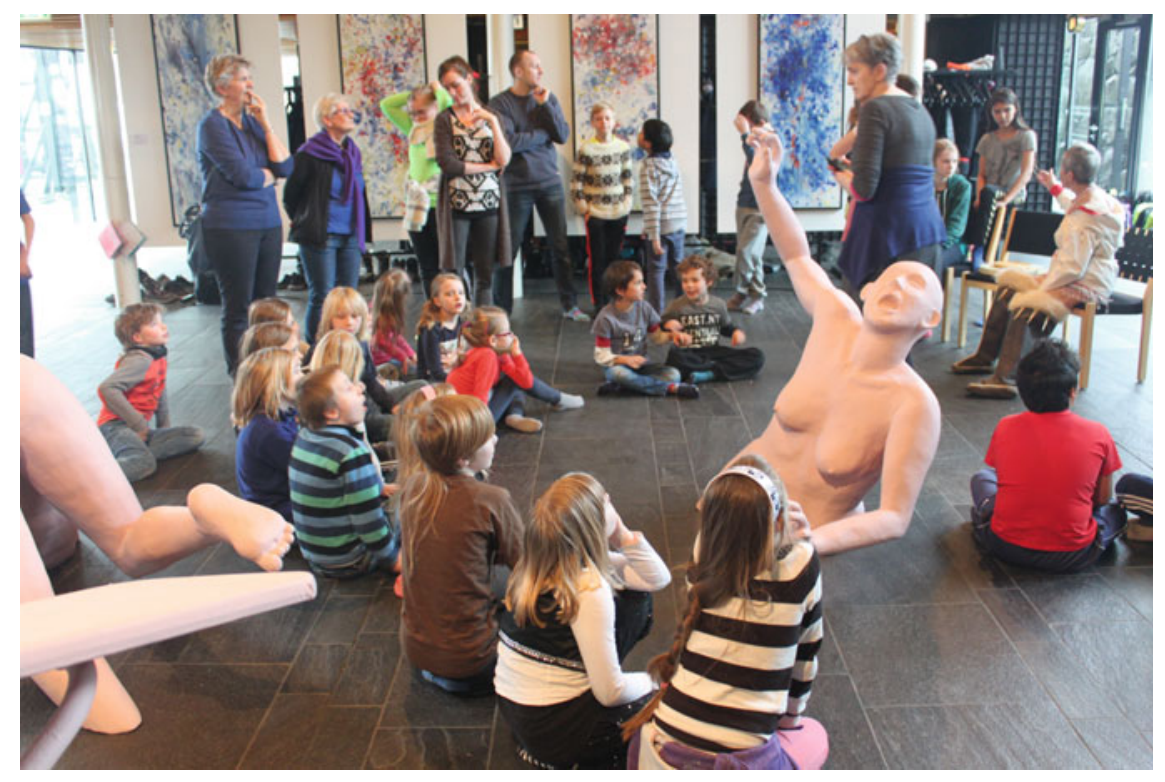

Fig. 18.4 Exhibition "Red Snow—When the Climate Bleeds" in Faroe Islands. School class visit. (c) Bente Elisabeth Endresen

children saw people panicking as the ice melted, standing with their bodies half covered in water. I was fascinated that this exhibition was actually able to talk to such young people about such serious matters."

With joy, we observed the youngsters revisiting the exhibition over the next few days, eagerly showing their parents around.

After visiting the project "Red Snow" in Reykjavik, Professor Kristin Vala Ragnarsdottir from the University of Iceland, invited me as a guest lecturer on a course at the university, entitled Sustainable Futures. Under her inspiring leadership, the students worked eagerly to find new, sustainable solutions to some of the serious problems facing the world. My contribution was to inspire to find new ways to convey information, in collaboration between art and science. Many students were familiar with artistic activities. It was uplifting to see the creativity they showed in finding both interesting new sustainable solutions and ways of communicating their ideas. For example, one young woman, who was an amateur dancer, gave a lively demonstration of how a dancer could perform to newly composed music on a theme illustrating how to work more in harmony with the Earth.

One of the project's guest speakers, on the Faroe Islands, was Lis Mortensen, a physical geographer at The Faroese Geological Survey (Jarðfeingi), who works with overcoming climate apathy. She is active in the new GeoSkúli project (e.g. O’Neill \& Nicholson-Cole, 2009, Mortensen \& Biskopstø Hansen, 2019) in the Faroes, where scientists work with young students, aiming to strengthen their understanding of the climate crisis and its consequences. Scientists highlight for the students how climate 
change is affecting their own local environment. They combine this with outdoor activities aiming to open up the young students' eyes and all their senses. In this way, they give the students more tools to help them relate to ongoing environmental changes on a much broader scale, such as desertification, sea-level changes and wilder weather. Lis Mortensen stated:

The project "Red Snow" brought together art and science and showed how rewarding it is to combine a scientific subject like climate change with art. When we observe climate and environmental change it is important to open our eyes and all our senses. Art has a special and engaging way of doing just that. We intend to bring the open approach from "Red Snow" into helping students in an engaging way, to learn about nature and local environmental change and then giving them the opportunity to visit these sites with open senses and observe for themselves, how their local environment has changed through time.

\subsection{Why and How to Establish a Fruitful Collaboration Between Science and Art?}

\section{"Logic will get you from A to Z; imagination will get you everywhere"- Albert Einstein}

Artists and scientists explore and illustrate their impressions and insights through totally different channels. Scientists reach people initially through our brains with logical information, often with a clear aim. Artists, on the other hand, appeal to our emotions through interpretation of various themes, giving more space for intuition, inspiration, imagination and creativity, and not necessarily working towards a specific goal. In 2013, the Louisiana Museum of Modern $\mathrm{Art}^{4}$ near Copenhagen, held an exhibition "ARKTIS" (2013), combining the work of artists and scientists in a mighty and multifaceted mosaic of impressions. Director Poul Erik Tøjner acknowledges the autonomy of artwork, but underlines that art can also play an active role in societal issues:

"Autonomy has nothing to do with irresponsibility towards the real world, or more or less
autistic moments of sheer joy, or fear or other kinds of private fantasies. Autonomy in my
ears has to do with defending or maintaining the specific character of art: its position, its
abilities to deal with things in other ways than those of science, religion or journalism".
(Where do we go from here, 2010)

Geology Professor Minik Rosing, from the Geological Museum and Natural History Museum at the University of Copenhagen took an active part in "ARKTIS". He stated:

I have always been interested in the relationship between art and science. Both activities are an attempt to understand the world we live in, and our own role in it. And to communicate this knowledge so as many people as possible benefit from it. In a wider sense, it helps a lot if research is something that can be retold instead of something that just involves numbers. ${ }^{5}$

\footnotetext{
${ }^{4}$ https://louisiana.dk/en/.

${ }^{5}$ https://uniavisen.dk/en/minik-rosing-keeps-on-finding-new-stories-beyond-the-horizon/.
} 
Another scientist, who calls for collaboration between art and science, is Paul Wassmann, professor in environmental biology at the Institute of Arctic and Marine Biology, at UiT -The Arctic University of Norway. He comments in an email conversation with the author:

A sustainable future is not possible through a one-dimensional, single professional approach.
To strengthen resilience and sustainable management, the world needs not only natural
science, but also multidisciplinarity. Although science appears to be the dominating force
today, we need more to communicate, eye to eye, with other disciplines and the general public.
Proceeding along roads that are already taken rarely results in augmented imagination and
innovative inventions. At crossroads one can scrutinize space and choose between alternative
routes".

A pan-arctic research network, ARCTOS, ${ }^{6}$ centred in Troms $\varnothing$, Norway, works with sustainable, knowledge-based marine ecosystems and climate change in the Arctic Ocean. The network attempts to build bridges between senior and junior scientists, national and international research, and between both industry and culture and science. ARCTOS has created conditions for meetings at what it calls "crossroads", such as, for example, the multidisciplinary conference Arctic Frontiers ${ }^{7}$ and the PolArt initiative, which each year gives 2-4 artists the opportunity of participating in an expedition to the Arctic Ocean, along with oceanographers and marine ecologists from UiT, UNIS, ${ }^{8}$ the University Centre in Svalbard and/or the Norwegian Polar Institute. ${ }^{9}$ In connection with the annual Arctic Frontiers Conference, artists are asked to exhibit the art that is inspired by their Arctic cruises. Some have also taken part in expeditions in favour of specific art projects, like the one providing the inspiration for the symphony "The sound of the Arctic", by composer Lasse Thoresen. $^{10}$

These examples show that there is currently a new awakening to the importance of art in raising awareness to climate change issues. It is gratifying that we as artists can make our contribution to this important work, both in small and in larger contexts.

\subsection{How We Are Affected by Visual Art, Music and Dance}

Music has a way of reaching deep into the human heart and opening up the senses. Music, singing, dance, art and creativity are basic to human life. Works of art speak to people's senses, whilst music and singing create a feeling of togetherness, joy and happiness. Expressing oneself through song, dance and art seems to be a basic need for individuals and for the human community.

\footnotetext{
${ }^{6}$ https://arctos.uit.no/.

${ }^{7} \mathrm{https} / / / \mathrm{www} . \operatorname{arcticfrontiers.com/.~}$

${ }^{8}$ https://www.unis.no/.

${ }^{9}$ https://www.npolar.no/en/.

${ }^{10} \mathrm{https}: / /$ www.youtube.com/watch?v=4vdTZF44HrY.
} 
When jazz legend John Coltrane first heard Charlie Parker play the saxophone, the music hit him "right between the eyes", he once said (Gabrielsen, 2013). According to neuroscientists, Coltrane was exactly right. A study has shown that when we hear music that we like, even for the first time, a part of the brain's reward system is activated (Zatorre \& Salimpoor, 2013). The region determines how much we value the song. A favourite song, whether a powerful rock anthem or a soulful acoustic ballad, evokes a deep emotional response.

Neuroscientist Valorie Salimpoor recalls once listening to Johannes Brahms's "Hungarian Dance No. 5" whilst out driving (Gabrielsen, 2013). The music moved her so profoundly that she had to pull over and stop the car. Intrigued by the experience, Salimpoor engaged in a study with Zatorre at McGill University's Montreal Neurological Institute in Canada to study how music affects the brain. They confirmed that dopamine, a reward neurotransmitter, is the source of such intense experiences, resulting in the "chills", associated with a favourite piece of music (Salimpoor et al., 2011). "They showed that listeners' dopamine levels in pleasure-centres surged during key passages of favourite music, but also just a moment before-as if the brain was anticipating the crescendo to come."

Brain researcher and musician Peter Vuust has had similar experiences. "Music is an integral part of life's highly pleasurable activities and has the ability to stimulate intellect as well as emotions" (Vuust et al., 2010). Researchers have not yet found a culture without music, which could suggest that music is essential to man. Historically, we have used music to create a sense of community. Music gives us a sense of togetherness, of not being alone in the world. If we tune in to a common energy, our wavelengths are harmonized during rhythm, dance and music. In periods of challenges, we have been brought closer together by playing music, dancing and singing together.

Music and community dance have proved to have a strong power in all societies. A good
example is the traditional ballad dancing in the Faroe Islands, which for centuries has united
the small nation so to say "in a ring" of song and storytelling. Travelling as a performing musi-
cian one experiences the value of the language of music, when meeting with audiences, orga-
nizers and other performers. There is often common ground for discussing and exchanging
ideas. However, the strongest language for communication is music itself. - Musician
Kristian Blak. ${ }^{11}$

In Denmark, when most social activities including choir singing, closed down due to the COVID-19 pandemic, we sang together. Danmarks Radio's (DRs) chief choir leader Philip Faber said: "At this time, we must stand together at a distance". He and DR found a musical solution for just this: They invented a concept of singing together from one's own home, school or workplace, every morning, with Philip Faber leading and accompanying the singing on the piano. This was broadcast directly via TV and radio, from the DR Concert Hall into the many homes and workplaces, where hundreds of thousands of Danes sang along: "at the same time, together and yet at a safe distance". To many, this resulted in a highly valued feeling of being part

\footnotetext{
${ }^{11}$ Interview of musician Kristian Blak by the author. https://www.kristianblak.com/.
} 
of a community, at a time when we were otherwise isolating ourselves to prevent infection. The community was at the centre and we were all a part of it. ${ }^{12}$

\subsection{Conclusions}

Art can be used as a means to inspire new ideas about how to establish a sustainable future for all. Through art, music, dance and creativity we can process impressions and express what cannot be said in words. Through creative play and expression one can find new ways of dealing with crises. Together, art and science can inspire visions and create images of possible future scenarios. When people can imagine a solution they can act on this vision. By immersing oneself in creative work, one opens the door to the subconscious which is often where truly innovative ideas emerge and through techniques of mindfulness and meditation, one can experience intuitive and inspirational new ideas, to work on.

In the Red Snow project, we saw younger participants reacting more spontaneously towards looking for solutions to what could be done to counteract climate change. One of the most impressive calls for climate action we have seen has come from millions of determined young people, all over the world. Inspired by Greta Thunberg, the well-known Swedish environmental activist, they have made their voices heard in a powerful way, by demonstrations in many of the world's major cities. Whilst climate scientists and others have been shouting in vain for decades, these committed young people have managed to get the world to put climate change on the international agenda. Most recently a film series has been made about Greta Thunberg, where she is partly seen in conversation with David Attenborough. The world-famous British documentarist has been filming the natural world for decades and in this way documented the changes that have been happening due to climate change. The world is finally waking up and hopefully the next COP in Glasgow in 2021 will see governments reiterating their commitment to a carbon-neutral world and agreeing upon policies that enable them to achieve their goals.

As is clearly seen in the examples above, there is also a huge number of adults of all ages, deeply concerned about the climate crisis and active in working for a regenerative civilization and thus for a better world. Integration is crucial, both between different professions, and between age groups. Only in working together can we hope to be successful in tackling the great challenges posed by the climate crisis and the acceleration of change we are witnessing. To rebuild the future we need teamwork. We must all ask, "What can we do - together - to contribute to sustainable development and a healthy planet"? As adults, with experiences in many relevant disciplines, we have a clear obligation to share our wisdom and knowledge and support the young people in their energetic and enthusiastic work, in every way, for a healthy planet.

\footnotetext{
${ }^{12}$ Interview with Phillip Faber, in Danish. https://drkoncerthuset.dk/dr-pigekoret/chefdirigent-phi llip-faber.
} 
Watching all the ideas emerging, and all the work being done to support sustainable living and pathways to regenerative civilizations, brings us hope for the future.

"The best way to predict your future is to create it. Not from the known, but from the unknown." —Dr. Joe Dispenza. ${ }^{13}$

A nineteenth-century proverb goes:

"We sow a thought and reap an act; we sow an act and reap a character; we sow a character and reap a destiny.”

\section{References}

Arktis (2013) Louisiana Revy, 54. year no. 1, September. Louisiana Museum of Modern Art, in print.

Gabrielsen, P. (2013). Why your brain loves that new song. Science April 11. https://www.scienc emag.org/news/2013/04/why-your-brain-loves-new-song

Mortensen, L., \& Biskopst $\varnothing$ Hansen, B. (2019). Keys to nature conservation: geoheritage and geotourism in the Faroe Islands" Frændafundur, Faroe Islands University, in print.

O'Neill, S., \& Nicholson-Cole, S. (2009). "Fear won't do it": Promoting positive engagement with climate change through visual and iconic representations. Science Communication, 30(3), 355-379.

Red Snow-When the Climate Bleeds. (2015). North Atlantic House, Copenhagen, in print.

Salimpoor, V., Benovy, M., Larcher, K., Dagher, A., \& Zatorre, R. (2011). Anatomically distinct dopamine release during anticipation and experience of peak emotion to music. Nature Neuroscience, 14(2), 257-262.

Vuust, P., Morten, L., \& Kringelbach, M. L. (2010). The pleasure of making sense of music. Interdisciplinary Science Review, 35(2), 168-185.

Where do we go from here. (2010). Papers from the Louisiana seminar. Louisiana Museum of Modern Art.

Zatorre, R. J., \& Salimpoor, V. N. (2013). From perception to pleasure: Music and its neural substrates. Proceeding of the National Academy of Sciences, 110(2), 10430-10437.

Open Access This chapter is licensed under the terms of the Creative Commons Attribution 4.0 International License (http://creativecommons.org/licenses/by/4.0/), which permits use, sharing, adaptation, distribution and reproduction in any medium or format, as long as you give appropriate credit to the original author(s) and the source, provide a link to the Creative Commons license and indicate if changes were made.

The images or other third party material in this chapter are included in the chapter's Creative Commons license, unless indicated otherwise in a credit line to the material. If material is not included in the chapter's Creative Commons license and your intended use is not permitted by statutory regulation or exceeds the permitted use, you will need to obtain permission directly from the copyright holder.

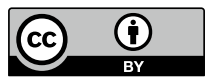

${ }^{13} \mathrm{https} / / /$ drjoedispenza.com/. 